\title{
TRANSPARENCIA EN LA ADOPCIÓN DE DECISIONES EN EL PROCESO DE INTEGRACIÓN EUROPEA
}

\author{
Elena F. PÉrEZ CARRILlO*
}

RESUMEN: Uno de los aspectos más relevantes en el intento de integración que se está produciendo en Europa desde finales de los años cincuenta, es el de conseguir que los ciudadanos del viejo continente, herederos de una historia que ha conocido luchas fraticidas y de diversas culturas políticas y sociales, se consideren no sólo informados de las transformaciones que estén ocurriendo, sino además, legitimados para solicitar e incluso para exigir acceso a la documentación, cualquiera que sea su soporte, que contenga datos e informaciones relativas a las políticas europeas, y a la adopción de decisiones en el seno de las instituciones supranacionales. El presente artículo ofrece una panorámica sobre el derecho de acceso a los documentos de las instituciones europeas, su introducción en los tratados constitutivos, su desarrollo en el derecho comunitario derivado y su reconocimiento en la Carta Europea de Derechos Fundamentales.

ABSTRACT: Among the aspects more relevant to the Integration process developing in Europe since the 50's one find the need that Europeans, heirs to a long history routed in wars, and belonging to many different social and political cultures feel that they are being fully informed of transformations taking place, that they are entitled to ask for access to any document which may contain data or in formations related to the European policies as well as those related to the decision making process in the Supra national Europe. This article offers a general panoramic sight on the Right of Access to Documents of the European Institutions in the light of the Treaties, the Regulations and the European Charter of Fundamental Rights.

RÉSUMÉ: Entre les questions les plus relevantes pour le succès de l'intégration européenne qu'a commencé dans les années 50, se trouve la nécessité de que les européens, dont la histoire est comblé de guerres et dont la culture est formée d'une mélange de différentes conceptions politiques et sociales, peuvent sentir qu'ils ont le droit de demander les documents qui contiennent informations relevantes pour les procès d'adoption des décisions dans les institutions supranationales, et des informations sur les politiques européennes. Cet article offre une vision général sur de droit d'accès aux documents des institutions européennes dans les traités, les règlements aussi que dans la Charte Européenne des Droits Fondamentaux.

* Universidad de Santiago de Compostela.

Anuario Mexicano de Derecho Internacional, vol. V, 2005, pp. 337-367 
Sumario: I. Ámbito objetivo. II. Ámbito subjetivo. III. Procedimiento de acceso a los documentos como mecanismo de la transparencia. IV. Control sobre las decisiones de denegar el acceso. V. Reconocimiento y evolución del derecho de acceso del público a los documentos en el derecho comunitario. VI. Perspectivas.

Desde su aprobación en mayo de 2001, el Reglamento Europeo sobre Acceso a los Documentos de las Instituciones Europeas, Reglamento 1049/2001, constituye la piedra angular del régimen de transparencia administrativa en la Unión Europea y responde al mandato establecido en el artículo 255 del Tratado de la Comunidad Europea, en la redacción adoptada en Ámsterdam en 1997. Por otra parte, la Carta Europea de Derechos Fundamentales proclamada en Niza en diciembre de 2002 reconoce la existencia de un derecho fundamental de acceso a los documentos, ratificado en el texto del proyecto de Tratado de la Constitución Europea.

\section{I. ÁMBITO OBJETIVO}

\section{Definición de documento}

El ámbito objetivo del derecho que vamos a analizar queda delimitado, por el momento y a la espera de que se pueda producir una reforma a través de un nuevo tratado: el "Tratado de la Constitución Europea", por dos normas. Por un lado y en el ámbito del derecho originario, por el artículo 255 del Tratado de la Comunidad Europea, en su redacción actual incorporada en Ámsterdam (TCE). Por otro lado y con carácter general o interinstitucional, en la norma de derecho derivado que desarrolla al anterior: el Reglamento 1049/2001. Adicionalmente, y sin perjuicio de que en estos momentos subsisten graves dudas sobre su calificación y naturaleza jurídicas, el artículo 42 de la Carta Europea de Derechos Fundamentales solemnemente proclamada en el Consejo de Niza de 2002 también debe ser mencionada.

Este ámbito objetivo del derecho de acceso de los ciudadanos a los documentos de las instituciones europeas está constituido, de conformidad con el artículo 255 TCE, por los documentos del Parlamento Europeo, del consejo y de la comisión, sin perjuicio de que puedan existir 
otros derechos subjetivos de acceso a otros documentos de otras instituciones y organismos.

El tratado no realiza una definición de documento, que sí se contiene en cambio en la legislación de desarrollo, y en concreto en el artículo 3 a) del Reglamento 1049/2001. Documento es, a estos efectos "todo contenido sea cual fuere su soporte". El Reglamento 1049/2001 establece una concepción amplia que mantiene la línea de las distintas decisiones sobre apertura y textos de soft law publicados en relación con esta materia en el transcurso de los años noventa. En vista de esta definición, el derecho de acceso abarca tanto los documentos en papel, como el almacenado electrónico, los contenidos tipo texto escrito, como la grabación sonora visual o audiovisual, etcétera.

Una vez admitido que cualquier contenido puede ser un "documento", hay que delimitar si el ámbito de acceso se refiere a los documentos elaborados por las instituciones (lo que nos llevaría a concluir en que estamos ante un "derecho de acceso según el criterio de la autoría"), o a los documentos que se encuentren en su poder (supuesto en el que estaríamos ante un "derecho de acceso según el criterio de la posesión"). Pues bien, mientras que el artículo 42 de la Carta Europea de Derechos Fundamentales se limita a enunciar el derecho a acceder a los documentos "de las instituciones" y de forma semejante, el artículo 255 TCE tampoco discrimina entre documentos elaborados por las instituciones, y documentos recibidos o en su posesión, el Reglamento 1049/2001, al establecer los principios de acceso, relaciona este derecho con el criterio de la "posesión". Esto quiere decir que todos los documentos que se encuentren en poder de las instituciones son en principio accesibles, salvo los que están afectados por alguna de las excepciones o limitaciones reconocidas.

La introducción del criterio de la posesión fue concebida a lo largo del proceso de gestación de esta norma como un indicio de mayor apertura frente al régimen vigente en los años noventa. En efecto, a raíz de la lenta y "tormentosa" aprobación del Tratado de Maastrich, los Estados firmantes anexaron la "declaración 17" a dicho tratado, que constituye el inicio de una nueva etapa caracterizada por el refuerzo de la transparencia institucional. Sobre esa base, ciertamente endeble desde un punto de vista meramente jurídico, pero bastante poderosa desde una perspectiva política, todas las instituciones y organismos de la Unión Europea habían aprobado una serie de normas de carácter fundamentalmente interno re- 
conociendo el derecho de acceso a los documentos elaborados por cada una de ellas, es decir, un acceso en función del criterio de la autoría.

Pese a la interpretación favorable al aperturismo que se quiso ver en los trabajos preparatorios del Reglamento 1049/2001, las excepciones introducidas y el régimen de permisos de terceros (infra) hacen que en la práctica el criterio de la posesión finalmente adoptado no resulte mucho más "aperturista" que el anterior.

\section{A. Documentos CECA y Euratom}

Dentro del objetivo de delimitar el concepto de "documento" (parlamento, consejo y comisión), debemos diferenciar los documentos de estas instituciones en tanto que actúan en el marco de la Comunidad Europea, y en tanto que operen en el de la CECA y Euratom.

El derecho aquí analizado abarca sin ningún tipo de dudas a los documentos del consejo, de la comisión y del Parlamento Europeo generados en el marco de la Comunidad Europea, ya que la base jurídica del Reglamento 1049/2001 es precisamente el artículo 255 del tratado constitutivo de esta comunidad. Ahora bien, la accesibilidad de los documentos CECA y Euratom está sujeta a otros matices. En virtud de la declaración 41 del Tratado de Ámsterdam, cuando estas instituciones actúen en virtud de la CECA y del Euratom deben inspirarse por los mismos principios establecidos en el TCE. ${ }^{1}$ De aquí puede deducirse que el derecho analizado se amplía objetivamente a los documentos CECA y Euratom. Sin embargo, a nuestro juicio, aunque probablemente la intención de los Estados al redactar el artículo 255 TCE, y la del legislador comunitario en relación con el Reglamento 1049/2001 haya sido el reconocimiento de un acceso amplio, sin restricciones, según cual sea la comunidad en la que operen las instituciones, la mera referencia en una declaración anexa al Tratado de Ámsterdam constituye una base jurídica insuficiente para reclamar un derecho fundamental o incluso un derecho subjetivo de ac-

1 La conferencia de representantes reunida para aprobar el Tratado de Ámsterdam adoptó una serie de declaraciones que constituyen anexos al acta final. La número 41 dice "La Conferencia considera que el Parlamento Europeo, el consejo y la comisión, cuando actúan a título del Tratado Constitutivo de la Comunidad Europea del Carbón y del Acero y del Tratado Constitutivo de la Comunidad Europea de la Energía Atómica, deberían inspirarse en las disposiciones en materia de transparencia, de acceso a los documentos y de lucha contra el fraude vigentes en el marco del Tratado Constitutivo de la Unión Europea". La referencia a la CECA debe entenderse en el marco de su expiración y correspondiente régimen. 
ceso a documentos CECA y Euratom. En este sentido, y con vistas a un futuro, cabe señalar que la ubicación del artículo $255 \mathrm{TCE}$, tal vez resultara más adecuada dentro de los artículos comunes a las tres comunidades (ahora dos, ya que la CECA, constituida en 1952 por un periodo de 50 años ha dejado de existir), es decir, dentro del articulado del Tratado de la Unión propiamente dicho, en lugar de ubicarse en el TCE.

\section{B. Documentos sobre justicia e interior y sobre política exterior y de seguridad común}

Dentro del ámbito objetivo del derecho de acceso es necesario determinar si alcanza también a los documentos elaborados o poseídos en el marco de la Cooperación Policial y Judicial en Materia Penal y los Asuntos de Justicia e Interior (JAI, tercer pilar) y de la Política Exterior y de Seguridad Común (PESC, segundo pilar). ${ }^{2}$

Por un lado, en el plano del reconocimiento como derecho fundamental, la redacción amplia de la carta no permitiría extraer conclusiones definitivas incluso si se llegase a determinar el carácter propiamente vinculante de la carta. Por otro lado, la ubicación sistemática del artículo 255 TCE indicaría que tales documentos no están incluidos en el derecho de acceso, puesto que éste se sitúa específicamente en el Tratado Constitutivo de la Comunidad Europea. Ahora bien, los artículos 28.1 y 41 del TUE señalan que el artículo 255 TCE resulta de aplicación a la PESC y la JAI respectivamente. Por tanto, hay que concluir en que el derecho originario o derecho europeo de los tratados sí que reconoce expresamente el derecho a acceder a los documentos de los pilares segundo y tercero.

El reconocimiento del derecho de acceso en el derecho derivado, el Reglamento 1049/2001, resulta sin embargo más limitado. En primer lugar porque se aprobó tomando como base jurídica el Tratado de la Comunidad Europea. En segundo lugar porque la única referencia que hace

2 Dado el carácter frecuentemente sensible y altamente confidencial de estos documentos, en particular cuando se refieren a la seguridad, tanto en el plano de la política exterior como en el de la cooperación judicial en asuntos de interior, se encuentran sometidos a procedimientos especiales, incluso en el marco interinstitucional. En este sentido, hay que destacar el acuerdo interinstitucional entre el parlamento y el consejo relativo al acceso del Parlamento Europeo a la información sensible del consejo en el ámbito de la política de seguridad y de defensa (DOCE C 298 de 30.11.2002), y la Decisión del Parlamento Europeo de 23 de octubre de 2002 sobre la aplicación de tal acuerdo (DOCE C 298). 
al segundo y tercer pilares se encuentra en el preámbulo (apartado 7), cuyo valor jurídico vinculante es cuando menos dudoso. De esta forma, a nuestro juicio parece que el derecho de acceso a documentos PESC y JAI no está plenamente desarrollado en el derecho derivado.

A pesar de ello, la jurisprudencia del Tribunal de Justicia ha reconocido el derecho de acceso a este tipo de documentos, incluso al amparo del régimen anterior al Reglamento 1049/2001. En Carvel y Guardian Newspapers vs. Consejo ${ }^{3}$ permitió el acceso a documentos relacionados con la justicia e interior, sin que a lo largo del proceso se planteara la incompetencia del tribunal por tratarse de documentos del título VI. En Svenska Jounalistförbundet $v s$. consejo, ${ }^{4}$ en que se dirimía el derecho de acceso a documentos PESC, el demandado opuso la falta de competencia del Tribunal de Justicia para decidir en asuntos relacionados con el segundo pilar. Pero, el tribunal, aún reconociendo que efectivamente no tiene competencia para decidir en asuntos relacionados con la PESC, señaló que ello "no obsta a su competencia para pronunciarse en materia de acceso del público a dichos datos".

En nuestra opinión, al margen de la existencia de las citadas resoluciones jurisprudenciales, el fundamento jurídico de un hipotético derecho subjetivo de acceso a los documentos de la PESC y de la JAI desarrollado por el derecho derivado es endeble y que convendría la aprobación de sendas decisiones estableciendo los principios y los limites de derecho de acceso en cada uno de dichos pilares. La interpretación del artículo 255 a la luz de los artículos 28.1 y 41 TUE, que ha guiado al Tribunal de Justicia en sus resoluciones, si que permite señalar que los documentos PESC y JAI se encuentran reconocidos en derecho originario, siendo conveniente que se clarifique su régimen a través de las normas de desarrollo oportunas.

\section{Excepciones}

Ni la Carta Europea de Derechos Fundamentales, ni el artículo 255 TCE establecen explícitamente los límites de este derecho. Por el contrario, éstas se contienen en el Reglamento 1049 de 2001. En primer lugar encontramos el artículo 4 del reglamento que contiene las excepciones 
propiamente dichas. En segundo lugar el artículo 9 establece un procedimiento especial de tramitación de documentos sensibles.

Antes de entrar a analizar cada excepción o limitación, hay que señalar que el artículo 4.6 del reglamento recoge las recomendaciones de la jurisprudencia anterior ${ }^{5}$ a 2001 , en el sentido de que las excepciones al acceso han de interpretarse restrictivamente, hasta el punto de que pueden afectar únicamente a determinadas partes del documento, a través de lo que se llama "acceso parcial". ${ }^{6}$

Por otra parte, cada una de las excepciones sólo se justifica durante el periodo en el que lo requiera el contenido del documento, y durante un máximo de 30 años, excepto en el caso de documentos sensibles, o relativos a la intimidad y a los intereses comerciales, en los que este periodo inicial es susceptible de ampliación.

Las excepciones al derecho de acceso se agrupan en cuatro categorías, de conformidad con el Reglamento 1049/2001.

\section{A. Basadas en el interés público, la intimidad y la integridad de la persona}

Esta excepción se encuentra contenida en el artículo 4.1 del reglamento, y contiene a su vez dos. Por una parte y por lo que respecta al interés público, se exceptúan del acceso los documentos cuya difusión pueda perjudicar la seguridad pública, la defensa y los asuntos militares, las relaciones internacionales y la política financiera, monetaria o económica de la comunidad o de un Estado.

Aunque no se dice expresamente, la excepción de seguridad pública constituye una fortísima limitación al acceso en los ámbitos de PESC y sobre todo de la JAI, ${ }^{7}$ ya que la posibilidad de afectar a la seguridad, de-

5 Consejo Europeo contra Heidi Hautala. Recurso de casación, asunto C-353/99.

6 T-211/00, Kuijer contra Consejo, párrafo 57 (interpretando el artículo 4, apartado 1, de la Decisión 93/731) establece que las excepciones al acceso deben efectuarse a la luz del principio del derecho a la información y del principio de proporcionalidad. En virtud de ello la institución de la que se ha solicitado el acceso está obligada a examinar si procede conceder un acceso parcial, limitado la denegación a los datos amparados por las excepciones, siempre que ese esfuerzo resulte proporcional.

7 El concepto de seguridad pública en la jurisprudencia comunitaria no tiene un único significado, y se refiere tanto a la seguridad interior de un Estado como a la seguridad exterior según se pone de manifiesto en la Sentencia del Tribunal de Justicia de 17 de octubre de 1995, Werner, C-70/94, Rec. I-3189, apartado 25), así como a la interrupción del abastecimiento de productos 
fensa y asuntos militares se producirá con más probabilidad en relación con la cooperación en materia de justicia e interior y en política exterior, y ello a pesar de la jurisprudencia proclive a reconocer el derecho. ${ }^{8}$

Esta primera excepción pone de manifiesto cierta incongruencia en el sistema de revisión judicial de las decisiones en el ámbito de la UE, en particular cuando se trate de aplicar a documentos del segundo y tercer pilares. El Tribunal de Justicia no tiene competencia para decidir sobre los asuntos del segundo pilar, y sólo cuenta con una competencia optativa en relación con los del tercero. Cuando el tribunal entre a dirimir sobre el alcance de esta excepción, su decisión podría considerarse como relativa al segundo o tercer pilares, por tanto excluida del ámbito de competencia del tribunal. Como venimos observando, esta cuestión ya ha sido resuelta por el Tribunal de Justicia que se ha manifestado competente. ${ }^{9}$ Sin embargo, la ausencia de lógica, que a nuestro juicio contamina estas decisiones, hace que una eventual norma de acceso específicamente relacionada con el segundo y el tercer pilares que nosotros consideramos necesaria, pudiese legítimamente limitar esta situación, es decir, restringir la posibilidad de revisión por parte del Tribunal de Justicia de las Comunidades Europeas

Dentro de este primer grupo de excepciones encontramos también las relativas a la intimidad y la integridad de la persona, que están relacionadas con la protección de datos. ${ }^{10}$ Por ello, ha de interpretarse de conformidad con el derecho comunitario derivado en materia de protección de datos, en concreto, según la Directiva 95/46/CE relativa a la Protección de las Personas Físicas en lo que respecta al Tratamiento de Datos Personales y a la Libre Circulación de estos Datos, ${ }^{11}$ la Directiva

esenciales, como los petrolíferos (Sentencia del Tribunal de Justicia de 100 de julio de 1984, Campus Oil y otros, 72/83 Rec. 2727, apartado 34).

8 Svenska Journalistförbundet vs. Consejo, Sentencia del Tribunal de Primera Instancia de 18 de junio de 1998, T-174/95, Rec.II-02289, apartado 120, en relación con el tercer pilar.

9 Svenska Journalistförbundet $v s$. Consejo, Sentencia del Tribunal de Primera Instancia de 18 de junio de 1998, T-174/95, Rec.II-02289, apartado 10.

10 Aunque no estamos ante una interpretación unánime, buena parte de nuestra doctrina considera que el derecho a la intimidad o el respeto a la vida privada tiene un contenido amplio en el que se incluyen intereses como el secreto de las comunicaciones, la inviolabilidad del domicilio, el secreto profesional, entre otros, y que alcanza a la protección de datos. Sobre el particular y en este sentido véase Ruiz Miguel, C., "La Carta de Derechos Fundamentales de la Unión Europea. Una perspectiva pluridisciplinar", Cuadernos del Instituto Rei Afonso Henriques de Cooperación, Herrero de la Fuente, A. (coord.), núm. 2, pp. 173-210, en particular p. 193.

11 DOCE L 281 de 23 de noviembre. 
97/66/CE relativa a la Protección de Datos en el Sector de las Telecomunicaciones, ${ }^{12}$ y con el Reglamento 45/2001 del Parlamento Europeo y del Consejo de 18 de diciembre de 2000 relativo a la Protección de las Personas Físicas en lo que respecta al Tratamiento de Datos Personales por las Instituciones y los Organismos Comunitarios y a la Libre Circulación de Datos. ${ }^{13}$ Habrá que tener en cuenta además, en la interpretación de esta excepción al derecho de acceso, la Decisión 1247/2002/CE del Parlamento Europeo del Consejo y de la Comisión de 1o. de julio de 2002 relativa al Estatuto y a las Condiciones Generales de Ejercicio de las Funciones de Supervisor Europeo de Protección de Datos.

\section{B. Basadas en intereses comerciales, procedimientos judiciales o de inspección, investigación y auditoría}

Esta excepción no resulta novedosa ya que el Código de Conducta de la Comisión y del Consejo de 1993 (norma de rango "interno" aprobada a raíz de la Declaración 17 del Tratado de Maastrich) ya establecía dentro de la excepción de interés público, los procedimientos judiciales, y las actividades de inspección e investigación. En su formulación actual, la protección de los intereses comerciales se relaciona con los de personas físicas o jurídicas incluida la propiedad intelectual; los procedimientos judiciales, el asesoramiento jurídico y las actividades de inspección, investigación y auditoría.

Frente a la excepción expuesta con anterioridad, ésta no se formula como una negativa automática o total. Por el contrario, si se demuestra que la divulgación reviste un interés público superior, pierde efectividad esta exclusión. La institución a la que se solicita el acceso debería realizar la valoración del balance de intereses, y en caso de que decida mantener la reserva de la información contenida en los documentos solicitados, los solicitantes pueden acudir al defensor del pueblo y al Tribunal de Justicia no sólo para justificar la inexistencia de la excepción, sino para hacer valer que la apertura conlleva un interés público superior.

La efectividad de esta excepción se puso de manifiesto en varios asuntos dirimidos por el Tribunal de Justicia. Por una parte en WWF UK $v s$. comisión ${ }^{14}$ donde se estableció que los documentos relativos a una in- 
vestigación sobre una eventual infracción del derecho comunitario por un Estado miembro están comprendidos en la excepción de interés público para no perjudicar el correcto desarrollo del procedimiento jurisdiccional; y en Pretrie y otros vs. comisión, en el cual un grupo de profesores de lengua solicitaban acceso a una serie de documentos de la comisión, para poder fundamentar otro recurso. ${ }^{15}$

\section{Basadas en el carácter interno de determinados documentos}

A través de esta excepción, las instituciones pretenden reservarse un thinking space o espacio para dilucidar su posición respecto de las materias afectadas por los documentos en cuestión. De alguna forma constituye el reflejo del carácter confidencial de las deliberaciones en órganos políticos y en órganos colegiados, reconocido también en los reglamentos internos del consejo, de la comisión y del Parlamento Europeo.

La jurisprudencia fundamentada en el régimen anterior a 2001 había establecido que el mero hecho de la protección del secreto de las deliberaciones no constituye un fundamento jurídico suficiente para denegar el acceso, sino que las resoluciones en las que se deniegue deben motivar el perjuicio que puede derivarse de la apertura. Se decía que tal justificación era exigible para proteger el derecho de los solicitantes a conocer las razones de la denegación, y de fundamentar una eventual solicitud a los tribunales de revisar la decisión denegatoria. ${ }^{16}$

Efectivamente, los reglamentos internos de las instituciones reconocen el secreto de las deliberaciones. Sin embargo, la introducción de esta excepción fue objeto de críticas en el trámite prelegislativo del Reglamento 1049/2001, ya que se consideró que supondría una fuerte limita-

15 Petrie y otros vs. Comisión, T-191/99. Los documentos solicitados formaban parte del expediente de un recurso contra Italia al amparo del artículo 226 TCE incoado por la comisión frente a la república italiana. Un grupo de antiguos "lectores" de lengua italiana están efectuando reclamaciones contra la comisión, por haber incumplido las sentencias Allué y Coonan de 30 de mayo de 1989, y Allué y asuntos acumulados de 2 de agosto de 1993 en los que el Tribunal de Justicia subrayó la incompatibilidad con el derecho comunitario de la utilización continua y sistemática de contratos temporales para satisfacer la enseñanza universitaria de lenguas. Se deniega el acceso porque "es esencial que (la comisión) pueda llevar a cabo investigaciones sobre cuestiones en las que esté directamente interesada como guardiana de los tratados al tiempo que respecta la naturaleza reservada de dichos procedimientos".

16 Entre otras sentencias C-350/88, Delacre y otros vs. Comisión, Rec 1990, I-395, párrafo 15; y T-105/95 WWF UK v. Comisión, Rec 1997, II-313, párrafo 66. 
ción del derecho de acceso reconocido hasta entonces. ${ }^{17}$ Pese a estas críticas, la excepción de "documento interno" se encuentra contemplada en el artículo 4.3 que establece que se denegará el acceso a documentos elaborados por una institución o recibidos por ella para su uso interno, o cuando se relacionen con algún asunto con el que la institución aún no haya adoptado una decisión.

En nuestra opinión la redacción de la artículo 4.3 no permite denegar el acceso a "todo documento interno", sino sólo a aquellos recibidos "expresa" y "exclusivamente" para "uso interno" y a aquellos cuya divulgación perjudique gravemente el proceso de toma de decisiones. Es decir que, al igual que las anteriormente expuestas, esta excepción está sometida a límites, si bien éstos no han sido desarrollados. A nuestro juicio, la institución que pretenda ampararse legítimamente en esta excepción para denegar el acceso debe probar (y exponer ante el solicitante) que se encuentra ante una de las siguientes situaciones:

Primero. Si el documento ha sido elaborado por ella misma, que está preparado "para uso interno". En este supuesto entraría en juego, a nuestro entender, la necesidad de justificar la concurrencia de alguna de las otras excepciones. En caso contrario, cualquier documento podría redactarse "para uso interno", escondiendo una clasificación arbitraria. Creemos que hubiese sido más adecuado que esta sección de la exclusión hubiese aludido a los dos tipos de documentos que consideramos en ella aludidos. Por un lado, a aquellos que "por su escasa entidad pueden ser destruidos", o que "por su escaso contenido podría ser generalmente reconocido que carecen de relevancia". Por otro lado, a los "documentos relativos al proceso de adopción de decisiones en los que concurren otras excepciones".

Segundo. Que no haya sido elaborado por la institución a la que se solicita el acceso en función del principio de posesión. En este caso deberá probar que el autor o la "fuente" del mismo la ha transmitido para "uso interno", denegando expresamente cualquier permiso de difusión a terceros. A nuestro entender, las reglas sobre permiso de autor a las que aludimos a continuación, entrarían en juego en este momento. Así, más

17 Las críticas a esta excepción se basan en la importancia de la transparencia para afirmar la democracia europea, y proceden sobre todo de la organización Statewatch, compuesta por diferentes grupos de asociados, entre ellos diversas asociaciones de periodistas. Pueden consultarse sus documentos de comentario del Reglamento 1049 de 2001 en www. Statewatch.com. 
que ante una denegación definitiva, estaríamos ante una exigencia de solicitar permisos antes de difundir.

Tercero. Que se trata de un documento relativo a un proceso de adopción de decisiones en el cual aún no ha recaído una resolución definitiva. Aquí estaríamos ante documentos cuya difusión dañaría a un proceso de toma de decisiones. Este tercer caso no constituye tampoco una excepción absoluta ya que el propio Reglamento 1049/2001 establece que si la divulgación reviste un interés público superior, debe permitirse el acceso.

\section{Basadas en la necesidad de solicitar el permiso de terceros}

El criterio de acceso en función de la posesión de los documentos que se introduce en el Reglamento 1049/2001 significa que en principio, cualquier documento que esté en manos del parlamento, de la comisión o del consejo es accesible. Por ello, esta excepción supone un aparente contrasentido cuyo efecto inmediato es que los documentos en poder de las instituciones comunitarias que hayan sido elaborados por terceros están sujetos a un proceso adicional previo a la apertura.

La institución debe examinar el contenido del documento solicitado de forma que si se deduce con claridad que puede ser revelado, éste será entregado o comunicado al solicitante de acceso como si fuese un documento elaborado por ella. Ahora bien, si una vez efectuado ese examen, el carácter accesible o restringido no queda claro, en virtud del artículo. 4.4, el respeto del derecho de acceso a documentos que hayan sido elaborados por terceros (ya sea otra institución, un Estado, una empresa o un particular) se traduce en una simple obligación de tramitar permisos.

Como una especialidad dentro de la necesidad de recabar el permiso del autor, el apartado 5 del artículo 4 establece la posibilidad de que cualquier Estado miembro de la unión solicite a la institución a la que entregue documentación que no la divulgue sin su consentimiento previo. Esta limitación que se encuentra en la declaración 31 del Tratado de Ámsterdam. 


\section{II. ÁMBITO SUBJETIVO}

\section{Beneficiarios}

Existen varias categorías de beneficiados. Un primer grupo está formado por los titulares propiamente dichos del derecho de acceso. Tienen reconocido un derecho subjetivo (en el tratado y en el Reglamento 1049/2001) y fundamental (en la carta) que no está sometido a la decisión discrecional de la administración. Dentro de este grupo encontramos a los ciudadanos europeos, es decir a los nacionales de cualquiera de los Estados miembros ${ }^{18}$ y de cualquier persona que resida o tenga su domicilio social en un Estado miembro. En caso de que la solicitud de acceso a documentos les sea denegada en su totalidad o en parte, en caso de que consideren que la resolución institucional que responda a su petición perjudica su derecho, o en el supuesto de que la institución o instituciones a las que soliciten documentos no respondan; estos sujetos cuentan con la tutela del ordenamiento comunitario para que tales resoluciones $\mathrm{u}$ omisiones sean objeto de revisión.

Por una parte, pueden acudir al defensor del pueblo, que pese a no contar con poder coercitivo ni sancionador es la autoridad supervisora del ejercicio del derecho de acceso en tanto que su obstaculización pueda constituir un acto de mala administración. Por otra, están legitimados para interponer un recurso ante el Tribunal de Primera Instancia.

Un segundo grupo de beneficiados lo constituyen los no ciudadanos y no residentes. No son titulares de un derecho fundamental o subjetivo que puedan oponer frente a la discrecionalidad de la administración, sin embargo están expresamente reconocidos como destinatarios de la potestad de las instituciones de conceder el acceso. En virtud del apartado 1 del artículo $195 \mathrm{TCE}$, estos sujetos no tienen la facultad de presentar una reclamación ante el defensor del pueblo debido a que ni son ciudadanos de la unión, ni tampoco residen ni tienen su domicilio social en ella. No

18 El concepto de ciudadano europeo introducido en el Tratado de Maastricht conlleva una serie de derechos: a circular y residir libremente en la unión, a votar, a presentarse como candidato en las elecciones municipales y europeas en el propio lugar de residencia, a recibir protección de las autoridades diplomáticas y consulares de otros Estados miembros en terceros países y derecho de petición. El derecho de acceso no se vincula, pues, a la ciudadanía, sino a la residencia. El artículo 17 del Tratado CE establece que será ciudadano de la unión toda persona que ostente la nacionalidad de un Estado miembro. En Ámsterdam se añadió que esta ciudadanía es complementaria de la ciudadanía nacional. 
obstante, sí que cuentan con un mecanismo para la revisión de la decisión administrativa de denegarles el acceso, ya que en virtud del párrafo 4 del artículo 230 TCE están legitimados activamente para interponer un recurso ante el Tribunal de Justicia.

Esta duplicidad de beneficiarios suscita la cuestión de si ambos grupos (ciudadanos y residentes frente a otros solicitantes) están amparados por derechos del mismo grado de intensidad. En nuestra opinión, el derecho de acceso, en tanto que derecho fundamental (artículo 42 de la Carta Europea de Derechos Fundamentales) y en tanto que derecho subjetivo (artículo 255 TCE y normas de derecho derivado que lo desarrollan) se reconoce sólo a los ciudadanos europeos y a los residentes en la Unión Europea, o a las personas jurídicas con domicilio social en la unión. La posibilidad de que los nacionales de o los residentes en terceros países obtengan documentos corresponde, a mi juicio, al ejercicio del poder discrecional de las instituciones y por tanto el juicio de valor jurisdiccional debería seguir criterios diferenciados.

\section{Sujetos obligados}

En la actualidad, el artículo 42 de la carta afirma el derecho fundamental de acceso a los documentos del parlamento, consejo y comisión. Si eventualmente se reconoce un carácter plenamente vinculante a este texto, estas tres instituciones serían los sujetos pasivos del derecho fundamental. Hay que señalar, no obstante, que de aprobarse el texto de Constitución Europea en la redacción presentada al consejo de Salónica en junio de 2003, el resto de las instituciones y organismos de las comunidades europeas quedaría también sometido a las reglas de transparencia. ${ }^{19}$

Los tres sujetos obligados, de conformidad con la carta, son los que encontramos en el artículo 255 TCE y en el artículo 1 del Reglamento $1049 / 2001 .^{20}$

19 Artículo II-42: Todo ciudadano de la unión o toda persona física o jurídica que resida o tenga su domicilio social en un Estado miembro, tiene derecho a acceder a los documentos de las instituciones, organismos y agencias de la unión, cualquiera que sea la forma en la que estén elaborados.

20 Este artículo indica que el Reglamento 1049/2001 fue aprobado precisamente para "definir los principios, condiciones y límites por motivos de interés público o privado por los que se rige el derecho de acceso a los documentos del Parlamento Europeo, del consejo y de la comisión referidos en el artículo 255 TCE”. 
Aunque no se dice explícitamente, el hecho de que la referencia se realice a esas tres instituciones (que participan en el triángulo de adopción de decisiones en derecho comunitario) implica que el ámbito del derecho de acceso a los documentos está íntimamente relacionado con la protección del interés de los ciudadanos por conocer los fundamentos de adopción de decisiones legislativas en la Unión Europea, un elemento básico y esencial de la transparencia. ${ }^{21}$ El resto de las instituciones (Tribunal de Justicia y Tribunal de Cuentas) ${ }^{22}$ y de organismos comunitarios también están llamados a adaptar sus reglas de acceso a los principios del reglamento, aunque no en virtud del articulado sino sobre la base de una serie de declaraciones cuya jerarquía es inferior. Por una parte en virtud del apartado 8 del preámbulo del Reglamento 1049/2001. Por otra, en virtud de la declaración anexa al reglamento, ${ }^{23}$ en la cual las instituciones manifiestan que el acceso a los documentos de las agencias creadas por el legislador se regirán por las normas del Reglamento 1049, y realizan dos mandatos para que la comisión proponga las modificaciones pertinentes en los reglamentos internos de estas agencias y para que el resto de instituciones y organismos procuren regirse por unos principios semejantes. ${ }^{24}$ Puede considerase que también nos encontramos ante una ampliación del ámbito objetivo, en el apartado 3 del artículo 18 del Reglamento 1049/2001 que realiza un mandato a la comisión para que examine la conformidad de las normas vigentes sobre el acceso a los documentos en otros organismos e instituciones.

Por lo que respecta a los Estados miembros, en tanto que la carta les resulte aplicable (cuando estos apliquen derecho comunitario), creemos que deberán respetar el derecho de acceso a los documentos de la comisión, el parlamento y el consejo. Además, puede afirmarse que éstos están sujetos a una obligación negativa en relación al derecho de acceso ya que de conformidad con el Reglamento 1049, cuando un Estado miembro reciba una solicitud para acceder a documentos que obrando en sus manos hayan sido producidos por una institución comunitaria, consultará

21 Sobre el acceso a los documentos comunitarios para conseguir la transparencia, Dyrberd, P., "El acceso público a los documentos y las autoridades comunitarias", Revista de Derecho Comunitario, julio-diciembre 1997, pp. 377 y ss.

22 Artículo 7 del TCE (Ámsterdam).

23 Declaración conjunta relativa al Reglamento (CE) núm. 1049/2001 del Parlamento Europeo y del consejo de 30 de mayo de 2001 relativo al acceso del público a los documentos del Parlamento Europeo, del consejo y de la comisión. Diario Oficial, núm. L 173, 27/06/2001, p. 0005-0005.

24 En estos momentos, la comisión ya ha presentado una propuesta de reforma del régimen de acceso que afecta a 15 agencias. Esta propuesta puede consultarse en COM (2002) 406 final. 
con ésta para no poner en peligro la consecución de los objetivos del reglamento, salvo que se deduzca con claridad que el documento en cuestión pueda ser difundido.

La inclusión expresa de los Estados entre los sujetos obligados a respetar este reglamento destinado fundamentalmente a las instituciones muestra la influencia de un asunto dirimido ante el Tribunal de Justicia, en el que se puso de manifiesto que la negativa de las instituciones a facilitar el acceso podía perder toda eficacia si los Estados entregaban tales documentos. Se trata del asunto conocido como "Svenska", 25 cuyos hechos subyacentes consisten en que tras la adhesión del Reino de Suecia a la Unión Europea el 1o. de enero de 1995, una asociación de periodistas suecos, la Svenska Journalistförbundet, se puso en contacto con 46 autoridades suecas solicitándoles acceso a un determinado numero de documentos del consejo relativos al establecimiento de la Oficina Europea de Policía Europol y obtuvo acceso a 18 de estos últimos 20 textos solicitados. A continuación, la misma asociación solicitó al consejo acceso a los mismos 20 documentos, pero éste sólo concedió el acceso a 2 de ellos basándose en la excepción de confidencialidad, por motivos de interés publico (seguridad publica) y por afectar a las deliberaciones del consejo. Pues bien, los demandantes hicieron públicos en Internet los documentos obtenidos a través del Estado sueco, a pesar de que se trataba de contenidos considerados confidenciales por el consejo.

\section{PROCEDIMIENTO DE ACCESO A LOS DOCUMENTOS COMO MECANISMO DE LA TRANSPARENCIA}

Ni la Carta Europea de Derechos Fundamentales, ni el Proyecto de Tratado Constitutivo, ni tampoco el derecho originario vigente aluden al régimen o al sistema aplicable al acceso. Hay que acudir, una vez más al Reglamento 1049 para conocer la previsión al respecto.

\footnotetext{
25 Svenska Journalistförbundet vs. Consejo, Sentencia del Tribunal de Primera Instancia de 18 de junio de 1998, T-174/95, Rec.II-02289. Este asunto fue particularmente interesante, porque puso de manifiesto las diferencias de interpretación en varios Estados. El Reino de Dinamarca, de Países Bajos y el Reino de Suecia entraron a coadyuvar a las demandantes. Mientras que la República Francesa y el Reino de Gran Bretaña e Irlanda del Norte participaron a favor de la demandada. A lo largo de la tramitación se produjo un incidente procesal debido a que la demandante había publicado en Internet cierta correspondencia recibida del consejo.
} 
El procedimiento para obtener el acceso consiste en un proceso de solicitud en dos fases (solicitud y "recurso administrativo") con la posibilidad de reclamación ante el defensor del pueblo y ante el Tribunal de Justicia. Los procedimientos fijados en este reglamento son vinculantes para las tres instituciones obligadas. ${ }^{26}$

Con carácter previo al análisis del procedimiento hay que indicar que cada institución está obligada a formar a su personal para que esté en condiciones de ayudar a los ciudadanos en relación con el ejercicio del derecho de acceso y a mantener un registro público de todos los documentos. ${ }^{27}$ Más que una novedad, estos mandatos suponen el reconocimiento de una práctica habitual que se desarrolla en la modificación de los reglamentos internos de cada una de las tres instituciones (supra). El artículo 15 del Reglamento 1049/2001 prevé, además, que a medida que se vaya adquiriendo práctica en el régimen de acceso, las instituciones deben ir estableciendo y asentando "buenas prácticas" relativas a su ejercicio. De esta forma se reconoce la escasa experiencia de las instituciones comunitarias en facilitar el ejercicio del derecho de acceso. Se reconoce también en sentido inverso (aunque no se diga explícitamente), que irán produciéndose "malas prácticas" que convendrá erradicar. En esta misma línea, el artículo 17 del Reglamento 1049/2001 establece la obligatoriedad de que cada institución publique anualmente un informe relativo al año precedente en el que figuren los casos en los que denegó el acceso y las razones de estas denegaciones, y si existen documentos sensibles que no estén registrados. El informe anual deberá hacer constar el número de tales documentos de cada institución. Adicionalmente, ordena a la comisión la publicación de un informe sobre la aplicación de los principios del reglamento, y la formulación de propuestas de reforma, en

26 Pérez Carrillo, E. F., "El derecho de acceso a los documentos en la Carta de los Derechos Fundamentales de la Unión Europea", Ruiz Miguel, C. (coord.), Estudios sobre la Carta de los Derechos Fundamentales, Santiago de Compostela, 2004, pp. 117-159.

27 Las obligaciones de informar, así como la referencia al registro vuelven a aparecer en el preámbulo (apartado 14), reincidiendo en una técnica legislativa ambigua en cuanto a sus efectos jurídicos. La modificación del reglamento interno y de las correspondientes normas anteriores sobre el acceso, vuelve a establecerse en el preámbulo, apartado 17. Las decisiones citadas son la 93/731/CE del consejo, la 94/90/CECA de la comisión, y la 97/632 sobre el Parlamento Europeo. En la misma línea, las instituciones están obligadas a la adaptación de su reglamento interno, que ya había sido contemplado en el artículo 255.3TCE, y a la modificación de las correspondientes decisiones de acceso de cada una de las tres instituciones. 


\section{el caso de que identifique áreas en las que el ejercicio del derecho resulte deficiente. ${ }^{28}$}

También con carácter previo hay que recordar que cuando la institución accede a permitir el acceso a los documentos solicitados, debe respetar las reglas de procedimiento que fijan los modos en los que tal acceso ha de producirse; y que cuando lo deniegue, ya sea de forma total o de forma parcial, ha de emitir y notificar al solicitante una resolución plenamente motivada ${ }^{29}$ respecto de cada documento o clase de documentos solicitados. ${ }^{30}$

El procedimiento general de acceso consiste en la puesta a disposición para la consulta in situ o en la entrega de una copia del documento solicitado, en la versión lingüística existente y en el soporte disponible (papel, cinta magnetofónica, etcétera). De existir varios soportes y varias versiones lingüísticas se hará en el preferido por el solicitante. ${ }^{31}$

28 El primero de estos informes anuales ya ha sido publicado, es el informe de la comisión sobre la aplicación de los principios del Reglamento (CE) núm. 1049/2001 relativo al acceso del público a los documentos del Parlamento Europeo, del consejo y de la comisión, Bruselas, 30.1.2004, COM (2004), 45 final.

29 En ese sentido se ha manifestado reiterada jurisprudencia, entre la que citamos por recoger buena parte de la anterior T-123/99, JT's Corporation Ltd. contra Comisión, párrafo 63: "Según se desprende de una reiterada jurisprudencia, la obligación de motivar las decisiones individuales tiene la doble finalidad de permitir, por una parte, que los interesados puedan conocer las razones de la medida adoptada con el fin de defender sus derechos y, por otra, que el órgano jurisdiccional comunitario pueda ejercer su control sobre la legalidad de la decisión. En el mismo sentido la sentencia del Tribunal de Justicia de 14 de febrero de 1990, Delacre y otros/Comisión, C-350/88, Rec. p. I-395, apartado 15; sentencia del Tribunal de Primera Instancia de 5 de marzo de 1997, WWF UK/Comisión, T-105/95, Rec. p. II-313, apartado 66). Para apreciar si la motivación de una decisión cumple dichos requisitos se debe tener en cuenta no sólo el tenor literal de la misma, sino también su contexto, así como el conjunto de normas jurídicas que regulan la materia de que se trate (sentencia del Tribunal de Justicia de 29 de febrero de 1996, Comisión/Consejo, C-122/94, Rec. p. I-881, apartado 29; sentencia Kuijer/Consejo, antes citada, apartado 36)".

30 T-123/99, JT’s Corporation Ltd vs. Comisión, párrafo 64. “Además, de la jurisprudencia se deduce que la comisión está obligada a examinar respecto de cada documento solicitado si, en vista de la información de que dispone, la divulgación puede suponer efectivamente un perjuicio para alguno de los aspectos de interés público protegidos por el régimen de excepciones (véanse, por analogía, las sentencias del Tribunal de Primera Instancia de 17 de junio de 1998, Svenska Journalistförbundet/Consejo, T-174/95, Rec. p. II-2289, apartado 112, y Kuijer/Consejo, antes citada, apartado 37)".

31 Cuando el acceso se realiza en papel, ya sea a través de envío o in situ las copias de menos de 20 páginas en formato DIN A4 y el acceso directo será gratuito. Sin embargo, las instituciones pueden exigir que el solicitante abone gastos correspondientes a envíos o a copias de más de 20 folios. 
Las solicitudes deben tramitarse con prontitud. Al recibirse la petición se envía un acuse de recibo al solicitante, ${ }^{32}$ y la respuesta para acceder o denegar el acceso debe producirse en el transcurso de 15 días, plazo que se amplía hasta un mes a instancias de la institución y por motivos tasados (voluminosidad y complejidad). En caso de que el solicitante no obtenga respuesta sobre su petición, ese silencio le da derecho a presentar una solicitud de "confirmación". Lo mismo ocurre en el caso de que le sea denegado el acceso total o parcial a los documentos solicitados.

La solicitud confirmatoria o de confirmación es el recurso ante un superior jerárquico contra la decisión de no conceder acceso. Los solicitantes tienen 15 días de plazo para recurrir administrativamente (en confirmación) contra la denegación. El plazo para resolver el recurso de confirmación es también de 15 días, que pueden ampliarse como en el supuesto anterior.

La denegación total o parcial al acceso solicitado, o el silencio administrativo permite el recurso ante el defensor del pueblo con arreglo al artículo 195 TCE, o ante el Tribunal de Justicia con arreglo al artículo 230 TCE.

Junto con los documentos accesibles existen otros restringidos, secretos o "clasificados" en función de que contienen información sensible. Hay que tener en cuenta que la decisión genérica sobre su grado de accesibilidad se produce generalmente en el momento de elaborar el documento, o en el momento de su archivo temporal, no con la solicitud del público. Esto implica que una denegación basada en el carácter clasificado de los documentos no debería nunca producirse en virtud de quien sea el solicitante. La mera constatación de que se solicita un documento clasificado no permite restringir automáticamente el acceso, sino que en todo caso la denegación deberá estar motivada en alguna de las excepciones ya citadas.

Los documentos "sensibles" están sujetos a un régimen especial que se basa en un sistema de clasificación dentro de una de las tres categorías

32 El reglamento fija un plazo de 15 días laborables a partir del registro de la solicitud para que la institución decida a favor del acceso, o para que comunique su decisión motivada de negativa total o parcial. Excepcionalmente el plazo puede incrementarse en otros 15 días laborables. Para ello deberá informarse al solicitante, y deberán explicarse los motivos de la ampliación. El reglamento se refiere a dos posibles motivos: la amplitud del documento solicitado, o el hecho de que el conjunto de la documentación pedida sea muy amplia y voluminosa, pero no específica si tales razonamientos son o no numerus clausus. 
siguientes: Tres Secret-Top Secret, Secret o Confidentiel. Esta categorización se encuentra en la decisión del secretario general del Consejo y alto representante de la Política Exterior y Seguridad Común de 27 de julio de $2000 .^{33}$

En el derecho comunitario, la clasificación de documentos debe responder a la protección de intereses concretos y no puede basarse en la mera legitimación del secreto administrativo, tradicional en muchos de los ordenamientos de derecho continental. Para fines del régimen de clasificación, almacenamiento y gestión de estos documentos, cada institución ha de designar un servicio responsable no sólo de la clasificación e introducción de datos sobre documentos sensibles en el registro, sino además de la asistencia y comunicación con los potenciales usuarios.

El procedimiento que deben seguir las instituciones a las que se soliciten documentos clasificados presenta ciertas especialidades respecto del procedimiento general anteriormente expuesto, y su tramitación estará a cargo de personas autorizadas expresamente.

Un último procedimiento de acceso, seguramente el que va a adquirir más relevancia es el acceso electrónico, en muchos casos directo. El Reglamento 1049 de 2001, en su artículo 11, establece la obligatoriedad de que las instituciones creen registros en los que se haga constar todos sus documentos. Desde finales de los años noventa ya existían este tipo de registros que fueron concebidos como bases de datos referenciales, es decir con referencias al documento en cuestión, pero no su contenido completo. A medida que pusieron en funcionamiento, las instituciones fueron introduciendo el texto completo de aquellos que eran puestos a disposición de algún solicitante. Así, una vez que se accedía a una petición de un documento interno, el resto del público tendría también acceso, incluso sin necesidad de solicitarlo expresamente de nuevo. En la actualidad, estos registros accesibles a través de las páginas $W e b$ de cada una de las instituciones contienen frecuentemente el texto completo de muchos de los documentos internos por lo que estos se ponen a su disposición, sin necesidad de tener que efectuar una petición individualizada.

33 Nos estamos refiriendo a la polémica "Decisión Solana" publicada en el DO C 239 de 23 de agosto de 2000 . 


\section{CONTROL SOBRE LAS DECISIONES DE DENEGAR} EL ACCESO

La solicitud de acceso puede concluir en la negativa de la institución a la que se le solicite de ofrecer tal acceso, negativa frente a la cual el interesado cuenta con una serie de mecanismos de revisión y control.

Desde la entrada en vigor de las primeras normas sobre transparencia, la posibilidad de los particulares de recurrir ante el defensor del pueblo ha situado a este organismo en un lugar muy importante en el control del derecho de acceso. La investigación de oficio publicada en 1996 en la que realizó un repaso del Estado del acceso en 15 instituciones y organismos $^{34}$ de la unión evaluando sus respectivos regímenes, y formulando recomendaciones constituye un texto de referencia para el análisis del derecho de acceso en la Unión Europea. Además, y puesto que la denegación de acceso puede considerarse como ejemplo de mala administración, el defensor es reconocido como órgano de reclamación frente a las denegaciones de acceso, aunque no tiene competencias para obligar a las instituciones.

Junto a la vía del defensor, otra posibilidad de recurso es la que puede plantearse ante el Tribunal de Justicia de las Comunidades Europeas. El recurso de anulación de la decisión que viole las normas sobre acceso puede interponerse en virtud del artículo 230 del tratado contra los actos adoptados por el consejo, la comisión, y los del Parlamento Europeo destinados a producir efectos ante terceros. En sus resoluciones, el tribunal realiza un control de legalidad, pero no puede dirigir órdenes conminatorias a las instituciones ni tampoco sustituir sus decisiones. ${ }^{35}$

La legitimación general para recurrir ante el Tribunal de Primera Instancia recae sobre cualquier persona física o jurídica destinataria de la resolución de denegación o afectada directa o individualmente por la misma. Como no existe un deber de justificar el interés al solicitar los documentos, en el recuso únicamente es necesario evidenciar la denega-

34 Entre ellos encontramos: El Parlamento Europeo, la comisión, el consejo, el Comité de las Regiones, el Comité Económico y Social, el Instituto Monetario Europeo, la Oficina de Armonización del Mercado Interior, la Fundación Europea de la Formación, la Fundación Europea de Formación Profesional (Cedefop), la Fundación Europea para la Mejora de las Condiciones de Vida y de Trabajo, la Agencia Europea de Medio Ambiente, el Centro Común de Traducción, la Fundación Europea de Lucha contra las Drogas y la Agencia de Evaluación de Medicamentos.

35 No corresponde al juez comunitario dirigir órdenes conminatorias a las instituciones, según reiterada jurisprudencia, entre otra Meyer $v$ Comisión, T-106/99, Rec p II-3273 apartado 21. 
ción de acceso, y la calidad de legitimado, sin que sea necesario justificar el interés. ${ }^{36}$

El plazo para la presentación del recurso es en virtud del tratado, de dos meses a partir de la notificación al recurrente, o a partir del día en que tuvo conocimiento, de conformidad con el apartado 5 del artículo 230.5 TCE. $^{37}$

\section{RECONOCIMIENTO Y EVOLUCIÓN DEL DERECHO DE ACCESO DEL PÚBLICO A LOS DOCUMENTOS EN EL DERECHO COMUNITARIO}

Los orígenes remotos del reconocimiento de un derecho de los ciudadanos a acceder a información relativa a la adopción de decisiones sin necesidad de tener que demostrar un interés concreto pueden relacionarse con diversos momentos de la integración europea. Buena parte de los esfuerzos desarrollados desde las instituciones europeas forman parte del interés por "acercarse" a los ciudadanos, que conllevó la puesta en marcha de proyectos que influirían en el incremento en la transparencia, como la creación de centros específicamente orientados a la difusión de la información y documentación comunitarias, en un enfoque de la transparencia

36 Así ha quedado señalado en abundante jurisprudencia, entre otras en Interporc vs. Comisión, T-124/1996, Rec. II-231, conocida como Interporc I de 6 de febrero de 1998, apartado 48 (se interpuso un recurso de casación - C-41/00 - en el que ya ha recaído sentencia que confirma la de instancia. También en Svenska, T-174/1995, Rec II-2289, apartados 65 a 67, y Petrie y otros $v$ Comisión, T-191/99, apartado 26.

37 Este plazo es interpretado de forma estricta según se ha puesto de manifiesto en sentencias como Athanasios Pitsiorlas contra Consejo. Asunto T-3/00.Rec 2001 II-00717 Athanasios Pitsiorlas contra Consejo de la Unión Europea y Banco Central Europeo. El demandante prepara el doctorado en derecho en la Universidad de Tesalónica y solicitó al consejo el acceso al Acuerdo "Basilea-Nyborg" sobre el reforzamiento del Sistema Monetario Europeo (SME), adoptado por el Consejo de Ministros de Economía y Hacienda el 12 de septiembre de 1987. La secretaría general le denegó su solicitud de confirmación pues "Las reglas relativas al funcionamiento administrativo del SME nunca han formado parte del derecho comunitario; en consecuencia, el Consejo no ha sido requerido en ningún momento para tomar una decisión al respecto". El consejo añadió la sugerencia al solicitante de que "dirija su solicitud directamente a los gobernadores de los bancos centrales o al BCE". El escrito del consejo fue notificado el 8 de agosto de 1999. El solicitante se dirigió entonces contra el BCE que mediante escrito notificado el 13 de noviembre de 1999, se le comunicó la decisión del consejo de gobierno del BCE de no concederle acceso al documento. La demanda ante el Tribunal de Justicia fue interpuesta el 20 de enero de 2000. El solicitante interpuso un recurso de casación en el que el 26 de septiembre de 2002 se han hecho públicas las conclusiones del abogado general (Asunto C-193/01) en las que recomienda la casación, por apreciar error excusable, debido a la redacción de la contestación del consejo. 
como difusión y "puesta a disposición". ${ }^{38}$ De una forma más explícita, en 1984 el Parlamento Europeo adoptó una resolución a favor de una mayor transparencia y apertura de las instituciones e incluyó una previsión sobre la apertura en el proyecto de tratado presentado por Spinelli que el Parlamento Europeo aprobó ese mismo año y que nunca llegó a entrar en vigor. ${ }^{39}$

Aún sin que se hubiese aprobado ninguna disposición específica de derecho originario sobre el derecho de acceso, el derecho derivado ${ }^{40}$ contenía desde antiguo normas y disposiciones relativas a la posibilidad (o a las restricciones) de acceder a documentos e informaciones en particular en ámbitos concretos como el de la competencia ${ }^{41}$ y el del medio ambiente. ${ }^{42}$ No obstante, hasta 1993 tampoco existía prácticamente ninguna legislación derivada sobre el derecho genérico de acceso del público a la información y documentación comunitarias.

A comienzos de la década de los años noventa se consideraba necesario realizar esfuerzos para cambiar la percepción que los ciudadanos de Europa tenían respecto de las instituciones comunitarias, así como para

38 Desde 1963 la Comisión de las Comunidades Europeas había establecido centros de documentación europea a través, principalmente, de acuerdos con las universidades europeas. $\mathrm{Su}$ objetivo era el de difundir documentos, fundamentalmente los publicados por la oficina de publicaciones de la comisión. Han contribuido a incrementar la transparencia en los trabajos de las instituciones y su cercanía a los ciudadanos. Estos centros juegan además un papel importante al servir frecuentemente de intermediarios para la solicitud de textos y documentos que permiten a los interesados obtener datos sobre el modo y las razones en virtud de las cuales se han adoptado decisiones. Al respecto, véase la página Web del Centro de la Universidad de Santiago de Compostela: $h t t p: / / w w w . u s c . e s / c d e$.

39 En general, sobre la evolución en el reconocimiento de este y otros derechos fundamentales en la Unión Europea, véase Ruiz Miguel, C., "El largo y tortuoso camino hacia la Carta Europea de Derechos Fundamentales", en id. (coord.), Estudios sobre la Carta de los Derechos Fundamentales de la Unión Europea, Santiago de Compostela, 2004, pp. 13-51.

40 Cabe destacar el Reglamento del Consejo de 1o. de febrero de 1983 sobre apertura de los archivos históricos (Diario Oficial, serie L 43 de 15.02.83), la Decisión de la Comisión de 7 de julio de 1986 sobre documentos clasificados y medidas de seguridad SEC (86) 1132 final, y el Reglamento del Consejo de 11 de junio de 1990 sobre datos comunicados a la oficina estadística de las comunidades europeas (Diario Oficial, serie L 151 de 15.06.90, p. 1), así como los reglamentos internos de las instituciones comunitarias, el estatuto de los funcionarios europeos, etcétera.

41 Normas sobre el acceso a la información en materia de competencia. XII Informe anual sobre la política de la competencia - en 1982-OPOCE, 1983, pp. 42 y ss.

42 Sobre el principio de información ambiental aplicable a los organismos comunitarios véase COM (88) 484 final de 28 de noviembre de 1988. La directiva 90/313/CEE del consejo de 7 de junio sobre la libertad de acceso a la información en relación con el medio ambiente (DOCE L 158 de 23.06.1990, p. 56) establece que cualquier persona física o jurídica puede acceder a la información en materia de medio ambiente, y el Reglamento (CEE) 1210/90 del consejo de 7 de mayo de 1990 sobre la creación de una Agencia Europea del Medio Ambiente y de una red europea de información y de observación sobre el medio ambiente. 
incrementar su transparencia y responsabilidad accountability. Es por ello que algunos han considerado que se estaba en "un momento constitucional de Europa". ${ }^{43} \mathrm{El}$ ambiente de crisis de confianza que rodeó la negociación y aprobación del Tratado de Maastricht contribuyeron a la formulación explícita de la necesidad de que la comunidad se "acercase a sus ciudadanos", ${ }^{4}$ así como a la aprobación de la Declaración 17 anexa a dicho tratado, en la cual los representantes de los Estados reconocieron que debía asegurarse el acceso público a los documentos para incrementar la transparencia, y solicitaron a la comisión la presentación de informes al respecto. ${ }^{45}$ Otros ejemplos de la reacción al clima de desconfianza y de euro escepticismo lo constituyen las conclusiones del Consejo Europeo de Birmingham, ${ }^{46}$ y del de Edimburgo, ${ }^{47}$ ya que en ellos se insistió en la necesidad de dotar de más transparencia al régimen de adopción de decisiones en la Unión Europea.

Sobre estos antecedentes, la comisión realizó estudios comparativos en materia de acceso a la información en los Estados miembros y en algunos países terceros, ${ }^{48} \mathrm{y}$ además adoptó una serie de prácticas como la

43 El momento histórico que coincide con el Tratado de Maastricht es considerado por algunos autores como fundamental en la evolución "hacia una Constitución para Europa". Weiler, J., "We will do and hearken", en The Constitution of Europa, pp. 3 y 4.

44 Además, los resultados de los refrendos para la aprobación del Tratado de Maastricht en Dinamarca y en Francia, y el estado de la opinión pública mostraron cierta dificultad para contar con apoyo popular para el proceso de integración europea, y se consideró que esta falta de apoyo se debía en gran medida a la opacidad en el trabajo de las instituciones comunitarias que podría remediarse incrementando la transparencia.

45 "La conferencia estima que la transparencia del proceso de decisión refuerza el carácter democrático de las instituciones, así como la confianza del público en la administración. La conferencia recomienda, por consiguiente, que la comisión presente al consejo, a más tardar en 1993, un informe sobre las medidas destinadas a mejorar el acceso del público a la información de que disponen las instituciones" (Declaración 17 anexa al acta final del Tratado de la Unión Europea firmado en Maastricht el 7 de febrero de 1992).

46 El Consejo Europeo de Birmingahn se celebró en octubre de 1992. La declaración sobre "Una comunidad cercana a sus ciudadanos" puede consultarse en el Boletín de la Comunidad Europea, núm. 10, 1992, p. 9.

47 El Consejo Europeo de Edimburgo se celebró en esa ciudad europea en diciembre del mismo año. En él los jefes de Estado y de gobierno se comprometieron a hacer la comunidad más abierta a los ciudadanos. Sobre estas conclusiones puede verse ibidem, pp. 7 y ss. Para un comentario sobre las conclusiones de estos consejos, véase Piris, J. C., “¿Son las instituciones comunitarias más eficaces, más democráticas y más transparentes después de Maastricht?”, Gaceta Jurídica de la CE, 1994, serie D, pp. 45 y ss.

48 Entre estos trabajos de la comisión en 1993, destacan por su relevancia en el proceso de apertura del acceso. Comisión Europea, El acceso de los ciudadanos a los documentos de las instituciones COM (93) 191 final, la Comunicación al consejo, al parlamento y al Comité 
publicación de sus programas anuales de trabajo, la promoción de debates amplios y la intensificación de las consultas previas a la elaboración de propuestas legislativas, que pretendían poner fin al pretendido "oscurantismo" que desde algunos foros se venía achacando a todo el sistema comunitario. Más importante como antecedente del régimen actual de acceso, fue la aprobación en 1993 de un Código de Conducta Interinstitucional del Consejo y de la Comisión. ${ }^{49}$ Carecía de carácter normativo pero sus postulados ejercieron considerable influencia porque sentó las pautas procedimentales que más adelante serían formalmente adoptadas por las instituciones: La Decisión 93/731/CE del Consejo de 20 de diciembre de 1993, relativa al Acceso del Público a los Documentos del Consejo; la Decisión 94/90/CECA, CE, Euratom de la Comisión de 8 de febrero de 1994, sobre el Acceso del Público a los Documentos de la Comisión; la Decisión 97/632/CE, CECA, Euratom del Parlamento Europeo de 10 de julio de 1997, relativa al Acceso del Público a los Documentos del Parlamento Europeo, así como otras decisiones que el resto de los organismos habían adoptado siguiendo el Código de Conducta de 1993..$^{50}$

La importancia y el reconocimiento del derecho de acceso del público a los documentos se incrementaron con la investigación de oficio iniciada en 1996 por parte del defensor del pueblo para esclarecer el grado

Económico y Social "Transparencia en la comunidad" COM (93) 258 final de 2 de junio de 1993, y "Una mayor transparencia en el trabajo de la comisión", en DOCE C 63 de 5.03.93.

50 DOCE L 340 de 31 de diciembre de 1993. En los DOCE L 23 de 1994 y 128 de 1998 se publicaron sendas rectificaciones. El Tribunal de Justicia no reconoce valor jurídico al código de conducta, si bien admite que el consejo podría tomar medidas destinadas a hacer frente a las peticiones de documentos que recibe, no obstante influyó decisivamente en las normas sobre acceso que adoptaron internamente las distintas instituciones europeas. Sobre el particular, véase Pérez Carrillo, E. F., "La transparencia en el funcionamiento de la Unión Europea. El acceso público a los documentos de sus instituciones y órganos", Revista Vasca de Administración Pública, núm. 56, 2000, pp. 349 y ss.

50 Pérez Carrillo, E. F., op. cit., nota anterior. En este artículo se pasa revista a las distintas normas sobre acceso que fueron aprobadas a lo largo de los años noventa, no sólo respecto de la comisión, Parlamento Europeo y consejo, sino también en relación con el Comité Económico y Social, Instituto Monetario, Tribunal de Cuentas, etcétera. 
de transparencia en el funcionamiento de las instituciones. ${ }^{51} \mathrm{El}$ defensor concluyó que todas las instituciones y organismos deben establecer procedimientos para facilitar el acceso, si bien reconoció determinadas restricciones relativas al Tribunal de Justicia y al Instituto Monetario Europeo, e incluso al parlamento, donde el principio de apertura y acceso sólo afectaba a documentos administrativos. Otro hito muy importante en la configuración del derecho europeo de acceso a los documentos lo constituyó la ampliación nórdica de 1995, y en particular el ingreso de Suecia, país con amplia tradición de apertura que había reconocido el derecho de los ciudadanos al acceso a los documentos que obren en poder de las administraciones públicas como derecho constitucional declarado en la Ley de Libertad de Prensa de 1766 (de carácter constitucional) modificada en 1949 y 1976, y en la Ley de Secretos Oficiales de 1980.52

\section{Pleno reconocimiento en el derecho originario}

La aprobación del Tratado de Ámsterdam supone una nueva profundización en la transparencia, ${ }^{53}$ según se reconoce expresamente en su preámbulo "El presente Tratado constituye una nueva etapa en el proceso creador de una unión cada vez más estrecha entre los pueblos de Europa, en la cual las decisiones serán tomadas de la forma más abierta y próxima a los ciudadanos que sea posible". Pero además, su artículo 255 TCE constituye la base jurídica explícita del derecho de acceso: "1. Todo ciudadano de la Unión, así como toda persona física o jurídica que resida o tenga su domicilio social en un Estado miembro tendrá derecho a acceder a los documentos del Parlamento Europeo, del Consejo y de la Comisión”.

Los consejos europeos siguientes a la aprobación del tratado muestran la preocupación de los Estados por ahondar en la transparencia. Así queda

51 En la Decisión del defensor del pueblo de 20 de diciembre de 1996, se concluyó que la carencia de normas y procedimientos para permitir que el público acceda a los documentos de las instituciones puede constituir un caso de mala administración. Sobre el particular véase el documento del Parlamento Europeo, 616/PUBAC/F/IJH.

52 Osterdahl, I., "Openness v. Secrecy: Public Access to documents in Sweden and the EU", European Law Review, 1998, 23 (4), pp. 336 y ss.; y documento de la comisión titulado "Overview of member states national legislation concerning public access to documents" (Directorate B, SG/B/2: Secretariat Général), de 9 de octubre de 2000.

53 Pérez Carrillo, E. F., "El Tratado de Ámsterdam. Entre el mercado de los quince y la Europa del s. XXI", Noticias de la Unión Europea, 186, julio de 2000, pp. 171-180; Bribosia, H., "Liberté, sécurité et justice: l'imboglio d'un nouvel espace", Revue du Marché Unique Européen, núm. 1, 1998, pp. 27-54. 
reflejado en concreto en las conclusiones de los Consejos de Cardiff de 16 de junio de 1998 que se refiere a la importancia de que Internet se convierta en un instrumento para incrementar la transparencia; de Tampere de 15 y 16 de octubre de $1999^{54}$ que recuerda que la integración europea está enraizada en la libertad y que ésta sólo puede ejercerse si los ciudadanos están bien informados y cuentan con un régimen justo de acceso; y de Helsinki de $11 \mathrm{y}$ 12 de diciembre de 2000 que vuelve a insistir en la transparencia como instrumentos para acercar las instituciones a los ciudadanos. ${ }^{55}$

Pese a la importancia del artículo 255 TCE el Tribunal de Justicia ha dejado fuera de toda duda el que no constituye una norma directamente aplicable puesto que no es incondicional y además incluye en sus propios términos el mandato de adopción de medidas posteriores. ${ }^{56}$

\section{El reglamento establece los principios y límites del derecho de acceso del público a los documentos comunitarios}

En respuesta al mandato de Ámsterdam, el 28 de enero de 2000 se hizo pública la propuesta de Reglamento de Desarrollo del artículo 255 TCE. ${ }^{57}$ A pesar del talante aperturista en el clima post Ámsterdam, esa propuesta fue objeto de debates y estuvo sujeta a muchas críticas. ${ }^{58} \mathrm{El}$

54 El Consejo Europeo de Tampere de 15 y 16 de octubre de 1999 recuerda que (apartado primero) "desde sus inicios la integración europea ha estado firmemente enraizada en un compromiso compartido de libertad...".

55 El Consejo Europeo de Helsinki se celebró en esta capital el 11 y 12 de diciembre de 2000. Son particularmente relevantes para nuestros propósitos los apartados 22 y 23 de este documento: "22. La transparencia de las instituciones europeas constituye un elemento importante para acercar la Unión a los ciudadanos y mejorar su eficacia. Durante la Presidencia finlandesa se han registrado progresos en especial en los que se refiere al acceso a los documentos y a una comunicación rápida mediante la utilización de las modernas tecnologías de la información. El Consejo Europeo ha acogido favorablemente la intención de la comisión de presentar en enero de 2000 la propuesta sobre los principios generales que regulan el acceso a los documentos del Parlamento Europeo del consejo y de la comisión". El apartado 23 se dedica a la subsidiariedad a la mejora de la calidad del proceso legislativo, aspecto íntimamente ligado con el del acceso.

56 Petrie y otros contra comisión, T-191/99, apartado 34. El tribunal señala que no son directamente aplicables puesto que no son incondicionales y además incluyen en sus propios términos el mandato de adopción de medidas posteriores, en concreto de la aprobación de la normativa que establezca los principios y límites de este derecho.

57 DOCE CE 177 de 27 de junio de 2000. Un primer comentario sobre esta propuesta y el debate que suscitó de inmediato puede consultarse en Pérez Carrillo, E. F., "La reforma del derecho de acceso del público a los documentos en la Unión Europea", Revista General de Derecho, 675, diciembre de 2000, pp. 14557-14580.

58 A pesar del talante aperturista, las nuevas disposiciones sobre el acceso a los documentos, la propuesta inicial que fue objeto de graves debates públicos presentaba algunas peculiaridades más 
Parlamento Europeo votó una serie de enmiendas a esta propuesta que la comisión no pudo aceptar, abriéndose una negociación entre instituciones antes de la clausura formal de la primera lectura, ${ }^{59}$ que permitió llegar a un acuerdo y a la presentación de una propuesta modificada por parte de la comisión. Coincidiendo temporalmente con la tramitación de la propuesta se publicó una decisión del consejo sobre clasificación de documentos sensibles, siguiendo una propuesta del secretario general. La irrupción de la llamada "Decisión Solana" supone un hito en la evolución del derecho de acceso porque refuerza el régimen de clasificación que supone un límite al acceso a determinados "documentos sensibles". ${ }^{60}$

El Reglamento 1049/200161 del Parlamento Europeo y del Consejo de 30 de mayo de 2001 relativo al Acceso del Público a los Documentos del Parlamento Europeo, del Consejo y de la Comisión entró en vigor el 3 de diciembre de 2001. Uno de sus primeros efectos es que obligó, de conformidad con el artículo 255.3 TCE, a reformar los reglamentos internos del consejo, de la comisión y del parlamento para adaptarlos al nuevo régimen, reforma que las instituciones ya han efectuado:

restrictivas que el régimen anterior y restringe el acceso a una serie de datos, que hasta el momento no eran objeto de tales limitaciones. En la propia definición de documentos, en la propuesta, Documento COM (2000) 30 final, p. 4 o "Propuesta de Reglamento del Parlamento Europeo y del consejo relativo al acceso del público a los documentos...", artículo 3, a), se hace constar que únicamente se encuadra en esta definición a los documentos "administrativos", sin que dicho término quede descrito. Por el contrario, otra serie de "informaciones" o "datos" no están incluidos en la definición. Además se excluyen de la definición de documentos, y por lo tanto quedan fuera del ámbito de aplicación de la norma los textos de uso interno, documentos de reflexión, documentos de debate, opiniones de los servicios y mensajes informales.

59 Tales negociaciones se realizaron en el marco de un diálogo informal a tres bandas a partir del 24 de enero de 2001, y dieron lugar a un texto de compromiso, aprobado el 25 de abril de 2001 por la Comisión de Libertades y Derechos de los Ciudadanos, de Justicia y de Asuntos Interiores del Parlamento Europeo, por el Comité de Representantes Permanentes de los Estados miembros (segunda parte) y por la Comisión Europea. En la sesión plenaria de 2 y 3 de mayo de 2001, el Parlamento Europeo adoptó enmiendas que modifican la propuesta de la comisión de acuerdo con el compromiso negociado entre las tres instituciones. La comisión las adoptó según se refleja en su propuesta modificada de Reglamento del Parlamento Europeo y del consejo relativo al acceso del público a los documentos del Parlamento Europeo, del consejo y de la comisión (presentada por la comisión con arreglo al apartado 2 del artículo 250 del Tratado CE), en COM (2001) 299 final.

60 Decisión del secretario general del consejo y alto representante de la política exterior y de seguridad común de 27 de julio de 2000, publicada en el DOCE C 239 de 23.08.2000. La Decisión del consejo de 14 de agosto de 2000 que sigue a la anterior fue publicada en el DOCE L 212 de 23 de agosto de 2000.

61 DOCE L 145 de 31 de mayo de 2001. 
La Decisión del Consejo de 29 de noviembre de 2001 por la que se modifica el Reglamento Interno del Consejo ${ }^{62}$ pretendió refundir los diversos textos sobre acceso a los documentos del consejo, y añadió un anexo a la Decisión 2000/396/CE, CECA, Euratom de Reglamento Interno del Consejo, que contiene tanto las disposiciones que no sufren modificaciones como las nuevas introducidas para adaptarse al Reglamento 1049/2001. Realiza numerosas remisiones al reglamento general, renueva la base jurídica del registro de documentos del consejo ${ }^{63}$ y además detalla determinados procedimientos, como por ejemplo el de solicitud de permiso a terceros, cuando sea preciso con el propósito de aplicar el artículo 4.4 del reglamento, o la tramitación de peticiones de consulta recibidas de otras instituciones.

La Decisión de la Comisión de 5 de diciembre de 2001 por la que se modifica su reglamento interno ${ }^{64}$ consta de dos artículos y un anexo de "Disposiciones relativas a la aplicación del Reglamento (CE) núm. 1049/2001". Entre las peculiaridades de esta decisión se encuentra el que aun confiriendo al secretario general la competencia para resolver las solicitudes confirmatorias, cuando se trate de documentos relativos a las actividades de la OLAF u Oficina Europea de Lucha contra el Fraude (actividades contempladas en los artículos 1 y 2 de la Decisión 1999/352/CE, CECA, Euratom), la decisión se delega en el director de esa oficina.

La Decisión de la Mesa relativa al Acceso del Público a los Documentos del Parlamento Europeo ${ }^{65}$ se une a la Decisión de 13 de noviem-

62 DOCE L 313 de 30.11.2001.

63 Aunque el Reglamento 1049/2001 haga referencia a la obligatoriedad de que las instituciones destinatarias del mismo (fundamentalmente la comisión, el parlamento y el consejo) creen un registro público, en realidad estos registros ya habían sido creados con anterioridad. En el caso del consejo, como consecuencia de la Decisión 2000/23/CE del consejo de 6 de diciembre de 1999 sobre la mejora de la información relativa a las actividades legislativas del consejo y el Registro Público de documentos del consejo (DOCE L 9 de 13 de enero de 2000).

64 DOCE L 345 de 2001.

65 DOCE C 374 de 2001. De conformidad con el artículo 172, apartados 2,3 y 4 del Reglamento Interno del Parlamento Europeo, corresponde a la mesa de esta institución la elaboración de normas destinadas a crear el registro de referencias documentales, así como a dotarle de un funcionamiento. Al igual que en el caso del consejo, el parlamento ya había creado un registro al amparo de la normativa anterior, y contaba con bases de datos como OEIL (observatorio de trabajos legislativos) y sitios Web como Europarl que permitían un acceso relativamente fácil a muchos de sus documentos. Ahora bien, las referencias en Europarl se orientan a documentos publicados. El efecto de la "re-creación" del registro es que la inclusión de documentos se hace obligatoria (con base en el 
bre de 2001 en el que adaptó el Reglamento Interno del Parlamento Europeo.

Pero no sólo las tres grandes instituciones legislativas se han adaptado, sino que el resto de los organismos comunitarios también lo han hecho al nuevo régimen general de transparencia. ${ }^{66}$

\section{El derecho de acceso como derecho fundamental}

La posibilidad de obtener información de las instituciones constituye un aspecto importante para el funcionamiento de una sociedad democrática, ${ }^{67}$ en tanto que permite el libre intercambio de ideas, ${ }^{68}$ y el control del ciudadano sobre el proceso de adopción de decisiones. Permite obtener informaciones esenciales para que los ciudadanos puedan ejercer una crítica al poder, y constituye un "derecho humano de tercera generación", perspectiva desde la que fue tenido en cuenta en el ámbito europeo con mucha anterioridad a la proclamación formal de la Carta Europea de Derechos Fundamentales. ${ }^{69}$

La Carta Europea de Derechos Fundamentales que fue proclamada en el Consejo Europeo de Niza de diciembre de 2002 incluye expresamente el reconocimiento del derecho al acceso del público a los documentos en su artículo 42 dentro del capítulo $\mathrm{V}$ dedicado a los derechos de ciudadanía. Su texto literal reza del siguiente modo: "Derecho de acceso a los documentos. Todo ciudadano de la Unión, o toda persona física o jurídica que resida o tenga su domicilio social en un Estado miembro tiene derecho a acceder a los documentos del Parlamento Europeo, del consejo y de la comisión". El Proyecto de Tratado de Constitución recoge el enunciado anterior, pero amplía el derecho de acceso a los documentos de "las instituciones, organismos y agencias de la Unión", y especifica que este derecho "alcanza a cualquiera de las formas en la que estén elaborados".

derecho originario y derivado, y no sólo de acuerdo con las normas del funcionamiento interno) respecto de "los documentos elaborados o recibidos... a partir del... 3 de diciembre de 2001".

66 Puede consultarse las normas de adaptación de estos otros organismos en http://europa.eu.int /geninfo/info/guide/index_es.htm\#access.

67 En este sentido, Dyrberd, P., op. cit., nota 21, pp. 377 y ss. Considera este autor que el derecho de acceso es uno de los componentes de la transparencia administrativa.

68 Osterdahl, I., op. cit., nota 52, pp. 336-356.

69 Comisión Europea El acceso de los ciudadanos a los documentos de las instituciones. Comunicación al consejo, al Parlamento Europeo y al Comité Económico y Social, COM (93), 191 final p. 11 . 


\section{PERSPECTIVAS}

El derecho de los ciudadanos europeos, y de los residentes en la Unión Europea a acceder a los documentos de las instituciones comunitarias goza de un razonable nivel de desarrollo, tanto en lo que se refiere a su ámbito positivo como a sus límites.

El reto de la integración europea que comenzó su andadura como un deseo compartido de consolidar un mercado común sobre una base fundamentalmente económica ha ido permitiendo alcanzar el consenso sobre los principios más amplios que deben guiar la actuación de la unión. En este contexto es enormemente importante que un derecho que no había sido reconocido expresamente en el ámbito comunitario hasta la década de los años noventa haya alcanzado un reconocimiento explícito y autónomo, no sólo dentro del derecho primario y secundario de la unión sino además entre los principios orientadores de la actividad comunitaria.

Las perspectivas del derecho de acceso a los documentos comunitarios no pueden ser más halagüeñas. La Carta Europea de Derechos Fundamentales proclamada por los Estados europeos en Niza en diciembre de 2002 lo contempla entre los derechos básicos de los ciudadanos europeos, y como tal ha sido recogido en el proyecto de Constitución Europea elaborado por la Comisión Giscard. Al margen del reconocimiento que se otorgue a ambos textos, lo cierto es que ambos son el resultado de un consenso sobre los principios que deben regir el futuro de la construcción europea que está aflorando en todo el continente, que el derecho de acceso a los documentos de las instituciones europeas está integrándose en una nueva "cultura" comunitaria, que facilita la cercanía y control de los ciudadanos sobre aquellos que desde Bruselas rigen sus destinos y que está desarrollando un papel cada vez más importante sobre la percepción de los ciudadanos del proceso de adopción de decisiones. ${ }^{70}$ Por ello, es importante resaltar que un derecho que ni siquiera había sido formu-

70 Sobre la importancia de los elementos culturales sobre la "constitucionalización" de los derechos véase, por todos, a Ruiz Miguel, C., "El constitucionalismo cultural", Cuestiones Constitucionales, núm. 9, julio-diciembre de 2003, pp. 201-216. También Ruiz Miguel, C., "Libertad religiosa, Constitución y cultura", Cuestiones Constitucionales, núm. 10, enero-junio de 2004, pp. 228-243. Son particularmente interesantes las referencias a los conceptos de cultura subjetiva y objetiva. En el caso del nuevo derecho fundamental de acceso, estaríamos ante la expansión de una noción "subjetiva", o de ámbito objetivo reducido (algunos países nórdicos) a una zona más amplia (toda la Unión Europea), que al irse reflejando en textos, pese al debate que se suscite en torno a su normatividad, va adquiriendo tintes objetivos. 